University of South Florida

DIGITAL COMMONS

@ UNIVERSITY OF SOUTH FLORIDA
Digital Commons @ University of

South Florida

$5-2003$

\title{
TDM in Europe: A Synthesis of Research Findings
}

CUTR

Follow this and additional works at: https://digitalcommons.usf.edu/cutr_nctr

\section{Scholar Commons Citation}

CUTR, "TDM in Europe: A Synthesis of Research Findings" (2003). Research Reports. 247.

https://digitalcommons.usf.edu/cutr_nctr/247

This Technical Report is brought to you for free and open access by the National Center for Transit Research (NCTR) Archive (2000-2020) at Digital Commons @ University of South Florida. It has been accepted for inclusion in Research Reports by an authorized administrator of Digital Commons @ University of South Florida. For more information, please contact digitalcommons@usf.edu. 


\section{Table of Contents}

Project Summary

$\begin{array}{ll}\text { Introduction } & 1\end{array}$

TDM Approaches to Terminating and Curtailing Traffic in Europe 2 Terminating and Curtailing Traffic through Parking Measures 2 Terminating and Curtailing Traffic through Road Pricing 3 Terminating and Curtailing Traffic by Alteration of Infrastructure $\mathbf{5}$

The Improvements and Promotion of Alternative Modes in Europe $\quad 7$ $\begin{array}{ll}\text { Public Transit Improvements } & 7\end{array}$ Mobility Centers $\quad 9$ Green Commuter Plans (GCPs) 10

Carsharing and Vanpooling $\quad 12$

Future Directions of TDM in Europe $\quad 14$

$\begin{array}{ll}\text { Conclusion } & 15\end{array}$

Annotated Bibliography of TDM in Europe $\quad$ A-1

Additional Resources on the Internet A-44 
TDM IN EUROPE: A SYNTHESIS OF RESEARCH FINDINGS

CENTER FOR URBAN TRANSPORTATION RESEARCH

\section{Florida Department of Transportation Summary of Final Report submitted by the National Center for Transit Research (NCTR)}

\section{FDOT Master Agreement Number FDOT BC137-38}

\section{RPWO Number:}

\section{NCTR Project Number: NCTR-473-132}

Final Report Date: May 2003

Project Title: “TDM in Europe: A Synthesis of Research Findings”

This report contains information on TDM strategies in the EU, specifically, but not limited to, the United Kingdom, the Netherlands, and Belgium. In addition, Europe's attitude toward TDM, as a journey rather than a destination significantly differs from the attitude about TDM in the United States. This synthesis reports on the major TDM approaches to terminating and curtailing traffic in Europe, such as parking measures (i.e., high prices for premium parking spaces and the elimination of parking spaces and auto access in certain areas to make car travel less attractive); road pricing (i.e., charging varying tolls according to time of day and also charging high enough tolls to influence driving behavior); and alteration of infrastructure (i.e., changing existing infrastructure to benefit nonmotorized travel). Further, many TDM organizations in Europe are offering positive incentives as well as the aforementioned negative incentives in order to curtail automobile traffic and congestion in major European cities. These incentives include public transportation improvements such as fare reductions, multi-user cards, expansion of current transit systems, easier transfers, shuttle service, feeder routes, increased speed and reliability, more access to fare cards at venues other than stations, and special routes to serve certain travel requirements. In addition to these improvements, European TDM strategies also include personalized travel via mobility centers. These prototype centers, located in major cities in the UK, Germany, and the Netherlands, offer more than 50 transportation services to clients, covering all modes available, including carsharing and vanpooling services. Finally, both companies and commuters can benefit from Green Commuter Plans. These plans provide incentives for both employers and employees to reduce auto travel to a worksite by providing an array of incentives, such as financial rewards for cycling, vanpooling, carpooling, or taking transit to work as well as provisions for telework and variable work schedules which benefit both employers and employees.

MOST (Mobility Management Strategies For the Next Decade) is an organization overseeing the implementation of pilot TDM projects in 32 European cities. The scope of the MOST project is to improve access to transportation for all sectors and to foster positive attitudes about alternative options toward sustainable mobility. MOST programs focus a large amount of resources on educational programs to enhance public awareness and to attract school children to transportation 
TDM IN EUROPE: A SYNTHESIS OF RESEARCH FINDINGS

CENTER FOR URBAN TRANSPORTATION RESEARCH

alternatives, before commuting habits are formed. MOST also is involved in shaping policy decisions such as changing tax laws to favor alternative mode use, changing land use rules to favor car-free spaces, and alteration of existing infrastructure to improve car-free options.

The purpose of this paper was to glean what the Transportation Planners in the U.S. could learn from TDM in Europe. In the U.S., policies could be made which would favor alternative mode use over private vehicle use in terms of taxation, land-use policies, and improvement of public transportation options. The Europeans have adopted and improved on U.S. TDM measures, such as carpool matching, vanpooling, and TMAs at employment sites. TDM is integrated into national transport policy in Europe, whereas in the U.S., TDM is only locally focused and operated for congestion relief and air quality management. Finally, TDM in Europe is marketed as a responsible lifestyle choice rather than as an alternative. However, TDM is also marketed in the U.S. as a responsible choice, but Americans have many more open spaces and less centralized living spaces than Europeans, as most American cities were developed after the advent of the automobile. And, it should be noted that there has been an increase in car use and ownership by Europeans in the past decade, even given their greater propensity to use transportation alternatives in comparison to Americans. Given the political differences, land-use differences, and space-availability differences between American and European cities it is to wonder if European-style TDM policies would be applicable and practical in the U.S. However, this report is interesting and informative as to the options available to Transportation Planners in the U.S., based on European advances in TDM. Additionally, this report contains an annotated Bibliography, listing many of the successful European TDM programs and what policies were used to implement them. Although the reader is cautioned that this synthesis does not contain an extremely broad approach to TDM in Europe, given that it is a short report, it does give the reader the overall texture and flavor of TDM policies and implementations in Europe and how this information might be useful to TDM professionals in the U.S. 


\section{TDM in Europe: A Synthesis of Research Findings}

\section{Introduction}

In searching for possible solutions to domestic transport concerns, Transportation Demand Management (TDM) professionals in the United States are becoming increasingly interested in mobility management practices in Europe. Attesting to Europe's growing reputation as an innovator in the field of mobility management is the amount of recent research not only about national incentives in countries such as the Netherlands, United Kingdom and Belgium, but larger scale efforts conducted within the European Union.

Though still in its incipient stages throughout most of Europe, Transportation Demand Management can at least be considered an interest for most countries within the European Union, a fact reflected in policies that are less frequently favoring road development and more often opting for management solutions that rely on sustainable modes of transport. In this manner, Europe's approach to TDM might be regarded as more prescient and future-oriented than the United States'. Much research and commentary from experts seem to suggest that the United States' response to mobility problems has been less anticipatory and comparatively reflexive; in other words, dilemmas are dealt with after they develop instead of before [34]. Likewise, the increasingly popular view of TDM in Europe as a continuous process distinguishes Europe's approach to mobility management from the United States'. In those countries recognized as innovative practitioners of mobility management---including the Netherlands, Belgium and United Kingdom--transport policy more frequently exhibits these enlightened attitudes.

In the past, TDM methods in Europe have typically focused on curbing private car use. In response to increasing private car use, Europe has deployed various mobility management methods, some similar to the United States', and others more recent in development and unique in approach. Whether through incentives or disincentives, European TDM has sought to reduce the attractiveness and affordability of car travel while increasing the practicality and desirability of relying on alternative modes. Strategies that increase the cost of car travel, including taxes, traffic tolls and parking fees, have been implemented in various cities to meet this objective. Conversely, other strategies have been deployed to decrease the price of public transport use and to enhance the experience of using these modes. Recent efforts have been devoted to the smooth integration of these modes through the alteration of infrastructure, the strategic placement of mobility information centers and stations and the creation of multipurpose travel cards. Moreover, emphasis has been placed on the encouragement of additional alternative modes, walking and cycling in particular. Other strategies such as the development of green commuter plans and employer-initiated journey plans are becoming more common throughout the European Union. More recently European TDM has relied on the relatively new approach of influencing travel behavior through advertising campaigns and marketing, encouraging citizens to make more conscientious travel choices while 
simultaneously targeting a younger, school-aged demographic before their travel habits have become routine.

These major trends are noticeable in research about European TDM, and will be explored in greater detail within this report. Less common but nonetheless successful measures will also be explained, and examples of European cities where these large and small trends have been adopted will be provided.

Some of this information will only be briefly related, but those readers requiring fuller detail may reference the annotated bibliography annexed to this report, covering research in which European TDM phenomena is given more thorough attention. Additional Internet resources are also provided at the end of the report.

\section{TDM Approaches to Terminating and Curtailing Traffic in Europe}

In those European areas where private car use is more common, congestion has not only affected the traveling time of the average commuter but has also contributed to air and noise pollution problems. These effects of congestion, combined with impact they have on Europe's economy, have led some European countries to take a more aggressive approach in the deployment of TDM methods. For example, one approach to the Dutch adoption of TDM is to remove cars from the international road network to allow for freer flow of goods from Rotterdam to the rest of Europe via truck. In the past, traditional TDM strategies have involved either halting or curtailing traffic. This section examines how several of these approaches work.

\section{Terminating and Curtailing Traffic through Parking Measures}

Aggressive parking strategies have played a vital part in Europe's effort to curb car use. Typically, strategies associated with the control of parking spaces have endeavored to influence travel behavior by limiting the number of parking spaces available and regulating the use of these spaces by imposing restrictions in terms of who can park there when and for what amount of time. In some cases, charges have been applied to parking spaces, decreasing the desirability of private car travel and eliminating many of the traffic problems that occur when drivers vie for limited amounts of space. A combination of the aforementioned strategies are often employed in European companies' "Green Commuter Plans," which will discussed later in this report.

Amsterdam can be considered one of the most aggressive cities in its enforcement of parking regulations; among its policies is a limitation of parking spaces new businesses are permitted to have in public transport-accessible locations. In the locations closest to public transport stops and stations, for instance, businesses are given no more than one parking space per ten employees, a restriction that has limited traffic in particular areas dramatically. This is actually a national policy called A-B-C policy.

In Italy, Bologna also discourages car use by way of parking restriction; drivers have to pay relatively high parking fees, residents can use certain parking spaces only, and in 
some cases residents even have to pay parking fees. Some sections of Bologna have access limited to residents, business owners and taxis only during designated hours, enforced by electronic equipment to verify vehicles have required permits [21].

Increasingly, companies and institutions are also using parking measures to alleviate onsite traffic problems. University of Sheffield in the United Kingdom, for instance, has incorporated into its travel plan the practice of dividing its car parks into categories, distinguished from one another by location, convenience, price and restriction. Car parks are divided into hierarchal categories, and permits for spaces are awarded on a points and criteria basis. Those commuters with the most points are given priority and allocated the most desirable spaces. Points are given to those who meet specified criteria and have commuter needs of higher urgency and priority; for instance, if a commuter has no access to public transport from his or her home, needs to travel by car for another reason, or has to take children to and from school, then he or she is given points. Though concrete statistics testifying to this plan's effectiveness are unavailable, evidence suggests a reduction in the number of staff and students driving alone to the school [1].

\section{Terminating and Curtailing Traffic Through Road Pricing}

Statistics indicate that most urban trips in Europe are made by car, and that private car ownership is continuing to rise. In the past, a typical response to these trends has been the construction of new roads and the creation of additional infrastructure; recently, however, TDM policymakers in Europe are regarding this approach as neither viable nor practical, and are instead more frequently opting for increasing the efficiency of existing road space. One method of optimizing infrastructure is through road pricing that influences commuter travel behavior.

Though few actual examples of road-based demand management exist worldwide, and despite the fact that road-pricing is still relatively rare in Europe, charging commuters for use of infrastructure is attracting attention as a means of deterring traffic. Testifying to this increased interest in road pricing, the European Commission has produced a "Green Paper" entitled “Towards Fair and Efficient Pricing in Transport” [24f] that delineates a fair and efficient pricing strategy:

- Charges should be linked as closely as possible to underlying costs.

- Charges should be highly differentiated to encourage behavioral adjustment.

- The price structure should be clear to the transport user.

- Charging should be non-discriminatory across modes and revenues should flow to authorities in countries where costs are incurred.

- Transport prices of journeys should be better aligned with the cost to society of these journeys.

- The full costs of all infrastructure networks should be recovered from the transport user in the long run, unless infrastructure has been constructed for other policy reasons.

- Imposing additional charges for simple revenue raising purposes is likely to lead to distortions. 
Due to these concepts, road pricing plans that recover at least a part of the economic tolls resulting from commuter journeys, congestion and pollution are likely to attract more interest among the EU member countries. Some road pricing plans, in fact, are already in varying stages of development within Europe. In Oslo, Norway, for instance, a method of charging cars electronically has been in practice since the late 1970s. The toll, charged to vehicles entering the center of the city and averaging approximately $£ 1.70$ per trip, generates about $£ 65$ million in revenue each year. While some research acknowledges that the reduction of traffic past the toll areas is modest---averaging about 2 to 5 percent--there has been increased use of public transit since the toll was initiated, indicating that the toll serves the purpose of not only recovering part of transport costs, but also functions as a viable disincentive to driving [21].

Other various forms of road pricing are currently in practice in European countries. In France, Italy, Greece, Portugal and Spain, motorway tolls now exist, and in the Norwegian cities of Bergen and Trondheim, urban-based pricing is underway. Commonly, these tolls generate revenues for the creation of additional infrastructure, or the maintenance of existing roads [25].

A less common practice is congestion tolling, a strategy meant to optimize the efficiency and use of existing infrastructure by distributing transport demand more evenly throughout commuter days. Toll prices fluctuate according to time and travel demand, reducing traffic during peak commuter hours. In Europe, Paris, France currently claims to be one of the few existing examples of a congestion-tolling scheme. To better ensure that weekend return travel traffic is more evenly and manageably spread, tolls are charged at strategic places and times [25].

Until recently, the tax system in the UK had failed to accommodate the development of mobility management strategies with a taxation regime that encourages alternative mode use and discourages private car travel. Besides road pricing and congestion tolling, however, a potential disincentive exists in a tax scheme that influences travel behavior. Despite slow and incremental changes in the taxation system, taxation in the UK has for the most part favored those who choose private car travel and discriminated against those who avoid private travel modes. Until early 1999, any financial incentive given to an employer in support of creating a travel plan for its staff was subject to income tax. In 2002, however, the UK's plan was to create a new taxation scheme based not only on a percentage of the company car's price, but its levels of carbon dioxide emissions. In the UK government's 1998 White Paper, “A New Deal for Transport: Better for Everyone,” [32] experts recommended against the building of new infrastructure and instead endorse mobility management approaches that are more progressive and feasible. One of these approaches is the government support of company green commuter plans in ways that reduce private car use and promote sustainable modes. The White Paper emphasizes the need for a revised taxation plan that assists in meeting this objective, and observes that some changes are already taking place that aid companies in the creation of commuter plans [33]. 


\section{Terminating and Curtailing Traffic by Alteration of Infrastructure}

Another control of traffic has involved the alteration of infrastructure to terminate or thin congestion, whether by decreasing road capacity and controlling space in a strategic way, or regulating existing space by implementing strategies that discriminate who and what kind of vehicles have access to this space [47].

A number of studies and resources, including those conducted by ADONIS and the research firms headed by Litman and Zeeger, have studied the potential of improving pedestrian conditions and encouraging walking [15]. Some measures and incentives include:

- Integrating nonmotorized planning into all transport and land use planning activities.

- Educating all transportation professionals in nonmotorized transportation planning principles.

- Funding nonmotorized planning at a comparable rate as other modes.

- Making sure that all roadways are suitable for walking unless it is specifically prohibited and suitable alternatives are available.

- Using current planning practices and design standards.

- Including nonmotorized travel in transportation surveys and models.

- Creating pedestrian-oriented centers and neighborhoods.

- Performing user surveys to identify problems and barriers to pedestrian travel.

- Using traffic calming and other traffic control measures to make street environments safer and more pleasant for walking.

Since 1995, the Danish Folketing, part of the Danish governing body, has allocated money to the Ministry of Transport's Traffic Pool. This money has been spent on initiating and supporting demonstration projects that can make traffic safer and less harmful to the environment, under the theme "Safer Bicycle Traffic." The projects demonstrate that road safety for cyclists can be improved, and that car trips can be changed into cycle trips if travelers are presented with the proper initiatives and cycling conditions [12].

Certain locales in Europe occupy the forefront of promoting pedestrian walking as an alternative to private car use. Pedestrianized, car-free commercial districts are becoming increasingly common throughout Europe, as evidenced in the Netherlands, whose "woonerfs" (literally translated "living yards", it means areas which are off-limits to vehicles, which could be used for a variety of alternative activities) number approximately 6,000. Other locales are more actively pursuing the creation of pedestrianfriendly environments, like Vienna's aesthetically pleasing areas filled with art, sculpture and fountains and Freiburg, Germany's sight-filled historical district, off limits to cars. The reconfiguration of neighborhood streets has also proven to make a substantial difference, such as Odense, Denmark's constraint of auto use to make parks and playareas for children [15]. 
Copenhagen, Holland has acquired a reputation as one of the most innovative cities in the realm of improving walking conditions. A testimony to Cophenhagen's achievements in this arena is the increased time people spend using the city's car-free spaces for a multitude of different activities, whether necessary for work or errands or optional leisure time. Data on these changes of urban culture have been recorded since the 1960s in a series of surveys and indicate major changes in traffic behavior and public life. Moreover, these surveys indicate that since 1968 car-free activities have quadrupled in the car-free zones of Copenhagen.

Through various measures and policies, Copenhagen has transformed the center of the city from a once car-dominated area to a place hospitable to pedestrian traffic and alternative, nonmotorized modes. Copenhagen’s first pedestrianized street, Stroeget, currently has about 80,000 people walking through a relatively narrow street (10 to 12 meters wide) during any summer day or night. Once a main street crowded with buses, lorries and cars, Stroeget was changed in 1962 to a pedestrian-only area. Surprised by the success of their experiment, traffic planners realized the potential of creating pleasant pedestrian space to reduce traffic problems. Since Stroeget opened to pedestrians, the amount of people staying in the pedestrian spaces has been growing proportionately with the number of car-free square meters that had been made available for pedestrians. Every time Copenhagen has added another $14 \mathrm{~m}^{2}$ for pedestrian use, a new person has come along and settled in to enjoy the city [39]. 


\section{The Improvement and Promotion of Alternative Modes in Europe}

This section reviews the literature that discusses how Europe seeks to improve and/or promote the use of various alternative modes to driving alone.

\section{Public Transit Improvements}

According to the research, a decline in the use of public transportation modes has been observed in recent decades. This phenomenon is not due to lack of availability, generally, but an increased accessibility to use of private transportation. The use of private cars is alluring to the general public because of a perceived sense of comfort, flexibility and security [24a]. In addition, company cars are very common and some countries provide tax breaks for the use of cars for commuting. In order for public transport to be utilized to its fullest potential as a means of combating congestion and curbing private car use, efforts need to be made in terms of changing the public's perception of this alternative mode and facilitating improvements to make public transport more alluring for commuters. The foremost objective of public transport services, according to many studies, should be the smooth and efficient integration of modes; instead of competing with one another, bus, tram and train services should cooperate to ensure that the public transport system operates efficiently, presenting to its users the least amount of obstacles and inconveniences possible.

Ideally, this integration of modes could be made even more user-friendly with the creation of cards that allow commuters to make transfers from one public transport mode to another relatively easily. The Netherlands, for instance, has recently created such a card, though it has been utilized on a relatively small scale, designed primarily for recreational travel. The project of the Gelredome stadium in Arnhern, Netherlands has proven successful in reducing car use, improving public transport accessibility, and promoting a cleaner environment. Contributing to this success was the creation of the "clubcard of Vitesse Arnhem," which allowed football fans free access to all bus services two hours before and two hours after each game. Primarily, the main goals of the Arnhem mobility plan have been to prevent parking problems around the stadium and ensure optimal traffic flow for visitors of the Gelredome [33].

Other studies indicate that a combination of different improvements is required to maximize public transport ridership. Among these improvements are:

- Fare reductions (e.g. off-peak or weekend reductions)

- New fare options, particularly discounted tickets and passes

- Free transit areas

- New and expanded transit systems

- More convenient routing

- Shuttle service, distributor routes, feeder routes

- More frequent service

- Increased speed and reliability 
- Longer service hours

- Regularized schedules

- Sale of transit tickets at employment sites, tourist offices, and other venues

- Special route to serve particular travel requirements, such as access to employment centers [17].

Despite high levels of private car ownership in much of Europe, public transport continues to be popular in locales such as Munich, Barcelona and Achterhoek, Netherlands (Public Transit Improvements). The UK Commission for Integrated Transport, an independent body set up by the government in the late 90s to rescue Britain's failing transport network, studied the public transport in these places and concluded what many other studies reinforce: that the largest contribution to success is a smooth integration of modes. Other qualities of the public transport systems in these areas, however, are noteworthy. Most importantly, a successful public transport system depends on an integration of policy-making and finance; land use, public finance and transport decisions need to be made in consideration of each other. Moreover, in order to decrease auto dependence, streets in municipal areas must be usurped from car users, and preferential treatment should be accorded to travelers who favor alternative modes instead of commuters who choose private travel [17].

Other areas regarded as having worthy models of public transport systems are Stockholm, 70 percent of whose trips are made on public transport during peak hours, and Utrecht, Netherlands, 80 percent of whose trips are either made on public transport or bicycle within the downtown area [22]. Cities such Utrecht owe part of their success to the locations of their stations, which often adjoin important urban areas and are within cycling distance to other destinations and attractions. Other cities like Stockholm have made efforts to create stations that are aesthetically pleasing to citizens, by renovating them and filling them with beautiful artwork [23].

Zurich, Switzerland's public transportation system combines some of the aforementioned strategies to impressive effect. Zurich's system provides 270 kilometers of line within the city and 262 lines covering 2,300 kilometers overall. The city's system is unique in that design features are given priority over other considerations, a decision made by the voting public. Buses have reserved exclusive lanes [23] and are equipped with electronic transmitters that allow the drivers to signal the vehicles' approach to traffic lights. Additionally, the routes of the public transit system are monitored with computers and commuters are provided accurate information about arrival and departure times. In addition to some of the aforementioned features, Zurich's is a smooth-running system because of the relative proximity of important areas to transit stops and commuters' ability to use a single ticket on any mode of transport throughout the city [23]. 


\section{Mobility Centers}

According to MOST (Mobility Management for the Next Decade), mobility centers are the nerve center of mobility management. On one hand they are the information point for all transport users with questions on sustainable transport, on the other hand they are the organizational core for mobility management and mobility services [46]. Momentum and MOSAIC, two research programs funded by the EU, have paid close attention to mobility management strategies implemented by members of the European Union in recent years. Of particular interest recently is the emerging trend of mobility management centers such as Münster's Mobilstations and Wuppertal's MobiCenter which promote the use of alternative transport and provide commuters with services such as timetable information, carpooling schemes, purchasing tickets and parking.

The MOSAIC (Mobility Strategy Applications in the Community) project [48], a threeyear research endeavor conducted through partners and demonstration projects in the UK, Germany and Netherlands. One of MOSAIC's primary demonstration projects focused on a mobility center in Wuppertal, a German city of approximately 400,000 citizens. When the MOSAIC project was initiated, the mobility center in Wuppertal became a focus of MOSAIC's attention. As a result, the center was allowed to broaden the range of services it had to offer. Currently, the Wuppertal center offers more than 50 services, covering all modes. According to the MOSAIC report, approximately one third of the population of Wuppertal is aware of the Mobility Center, largely due to its central location in the heart of the pedestrian zone. The best-known Mobility Center services were those related to public transport. Auto-related services provided for the MOSAIC pilot project, such as car sharing or information on available parking spaces, were less well-known [48]. An estimated 1\% of Wuppertal citizens are users of the mobility center services, the typical clients being licensed, employed females who do not own cars. By the MOSAIC project's conclusion, there was a small but identifiable shift from private to public transport [48]. More recent information, however, indicates that the MobiCenter of Wuppertal is swiftly gaining attention and users, since the degree of knowledge about the center grew to 40 percent among Wuppertal citizens in 2000. Over half of the citizens who knew about MobiCenter have used its services [46].

Another mobility management center, Münster's "mobile," was initiated in the late nineties. Located in the center of the city, "mobile" offers a range of information services to its users, and recent research indicates that $8 \%$ of these customers have altered their travel habits after consultation. It is Münster's plan in 2002 to combine existing information centers to create a larger and more extensive center across from the central station, an improvement that can reasonably be expected to increase the number of customers who utilize and are affected by the service [46].

Other mobility centers in Europe include Bologna, Italy's center, which has been in existence since 1995 and has been offering information of alternative and multiple modes since 1998. At the Bologna center, a customer satisfaction survey is conducted annually, and the number of people utilizing the service is estimated every month [46]. Within 
close distance to the University and Academic Hospital, Utrecht's Mobility Office aimed to reduce commuter car use and increase accessibility to the area. One of the service's primary objectives was to provide transport management information to participating companies. Based on surveys, the MOSAIC report concludes that between 1992 and 1994, the trip distance traveled increased for all modes at the university but decreased slightly at the hospital. The use of cars for business trips had declined at the university, while public transportation use remained stable [48].

\section{Green Commuter Plans (GCPs)}

Increasingly, companies throughout Europe are implementing green commuter plans (GCPs), adopting a series of strategies that, when combined, reduce a company's transportation problems and influence the commuting behavior of employees and visitors. In the U.S., these plans are often called Transportation Management Plans or Trip Reduction Plans. Based on Rye's report, the MOSAIC projects, and other related research and demonstrations, company, site-level action is becoming increasingly common, and the success of GCPs depend both on a balanced combination of measures and a blending of incentives and disincentives. Companies more actively seek GCP solutions to transport problems when there are dilemmas to surmount, such as parking shortages, site congestion and planning problems. Commonly, companies require the catalyst of a travel problem to be spurred into the contemplation phase of GCP development. In order to achieve the initiatives delineated by its travel plan, a company may incorporate a range of transportation-related initiatives to address different transportation aspects, including commuter journeys, business travel, and fleet management. A company can incorporate into its plan a broad package of complementary measures, depending upon the goals of the plan [1]. These measures include an array of incentives and disincentives, such as provision for cycling, teleworking and carpooling, as well as limitation of parking and changing of work conditions. The UK government requires GCPs of county councils and for new developments.

The Greater Nottingham area, 190km north of London with a population of roughly 600,000 inhabitants, was the focus of some MOSAIC demonstration projects that encouraged local employers to adopt green plans. Part of this effort involved MOSAIC's recruitment of a mobility consultant, funded by MOSAIC, to introduce the idea of green commuter plans to these employers. Typically, the Nottingham consultant contacted these businesses via letter; the task of developing a travel plan, however, was left largely to the employers. The Nottingham consultant's only contribution to the process was the suggestion of possibilities. When this demonstration project was completed, MOSAIC then began the process of assessing the effectiveness of promoting green commuter plans through the mobility consultant. According to the MOSAIC report, "Only 6 of the 36 'not contacted' organizations had heard the term 'Green Commuter Plan' before and over half of the other organizations first heard the term through contact with City Council.

Reactions to the initial meeting with the Mobility Consultant were positive with 9 of the 19 organizations interviewed who had a meeting describing it as very useful and 6 as quite useful. The majority of the 23 Active organizations thought that the level of assistance they received from the City Council on Green Commuter Plan issues was what 
they needed" [48]. At the time of the MOSAIC report's completion, 32 of 108 possible organizations were working on green commuter plans. Ten of these organizations were already involved in the initiation of a green commuter plan before being contacted by MOSAIC's mobility consultant; the remaining 22, however, were encouraged to create incentives and disincentives to achieve a reduction of car use [48].

In his report Management of Staff Travel Choices at the Company Level in the UK, Tom Rye [1] provides several examples of existing travel plans that typify methods of the practice in its various forms:

- University of Sheffield. University of Sheffield has incorporated into its travel plan the practice of dividing its car parks into categories, distinguished from one another by location, convenience, price and restriction. Parking permits are granted on a points and criteria basis. Rye [1] grants that even though concrete statistics testifying to the plan's effectiveness are unavailable, evidence suggests a reduction in the number of staff and students driving alone to the school.

- Nottingham City Hospital. The measures of Nottingham City Hospital's travel plan include:

o Improved pedestrian and cycle access to the hospital

o Installation of showers and lockers, as well as improved bicycle parking

o Arrangements with bus service providers to arrange city routes with respect to the location of the hospital

o Parking charges, with a portion of the revenue invested in improving non-car based access to the hospital

- Fife Council, Scotland. Measures utilized by Fife Council include:

o Offering secure bicycle parking, lockers, showers and public transport information

o Use of a carpool matching database

o Reservation of car spaces for carpoolers

- Hewlett Packard, Edinburgh, Scotland. The primary components of Hewlett Packard's travel plan are:

o Bicycle parking and access to lockers and showers

o Preferential parking for carpoolers, based on number of passengers

o Carpool matching databases

o A discount of up to $40 \%$ on rail tickets, achieved through the company's negotiations with Scotrail

o Information and promotion of non-car based modes

o Gradually eliminating company cars and/or replacing them with environmentally-friendly vehicles

- Stockley Park Business Park, near Heathrow Airport, West London. The aspects of business park's plan have included:

o An internet site with travel information

o Travel coordinator/s

o Support of key bus services 
o Dissemination of information and publicity

o Staff surveys

o Financial investments in further sustainable transport solutions, including the development of a new railway station

- Gyle/New Edinburgh Park. Rather than a single organization or company, the Gyle/New Edinburgh Park is a large employment area consisting of numerous companies, as well as a major shopping center. The combined actions of the park's travel plan have included:

0 Gathering and sharing data

o Lobbying public transport providers

o Lobbying the local council for better parking control

According to Rye [1], Nottingham City Hospital reduced its individual car commuting by 17\% between 1997 and January 2001. In Stockley Park, car use decreased from 88\% to $84 \%$, and cycling use more than doubled. Moreover, a modal shift from car to rail was evidenced at the Hewlett Packard demonstration, where the number of employees commuting alone dropped from 65\% to 59\%.

\section{Carsharing and Vanpooling}

In Europe, carsharing companies and vanpooling services are propagating at a healthy rate. Carsharing is a form of a vehicle rental or fleet operation where travelers have instant-access to a network of cars throughout a city, 24 hours per day and pay per trip. Carsharing is more common in Europe compared to the United States, though carsharing companies and practices are increasingly being developed throughout North America. In Europe, carsharing organizations typically charge \$1-2 per vehicle hour, plus 25-40 cents per mile. Some carsharing operations also charge a membership deposit of \$300-500, typically refundable. These charges usually cover all vehicle-operating expenses, including fuel and insurance. Often, special rates are designed for extended trips and infrequent users. The creation of all-inclusive packages and specially tailored rates has led to an increase in European carsharing, but other barriers include adequate education and marketing, as well as a need to establish and maintain a regular and substantial clientele [18].

In his State of the Art report, Roy Traue [10] provides examples of what he feels to be representatives of carsharing innovators. German CarPool, for instance, “offers open end, instant access and one way rides. Apart from CarPool, no regular carsharing system across Europe includes open end or instant access”. Traue [10] also describes as state of the art a type of access-technology that allows a customer to reserve his or her car by phone or Internet, among other options, and this order in turn is transmitted via computer to the on-board computer within the customer's car of choice. "The customer then has to put his smart card in front a reading device behind the car's windshield or incorporated into the key-locker. The car or locker only opens if there is a valid reservation registered for the corresponding customer and if the customer types in the right PIN. After the trip, the respective data are transferred back to the local branch office where an automatic billing is carried out” [10]. 
In Switzerland and Germany, car sharing (also called station cars) has been a transportation offering for more than 10 years. Presently, Mobility CarSharing Switzerland serves more than 20,000 people at 600 stations in 300 cities and towns throughout Switzerland and manages a fleet of 900 cars. Already some mobility services exist in Europe, such as Autodate in the Netherlands, which attract more than 85,000 customers. At present, many transit agencies, CSOs, and mobility centers are beginning to provide a variety of car sharing products and other mobility services based on smart cards and communication technology [36].

A less common phenomenon in Europe is vanpooling. In early 1995, the Dutch Ministry asked Organizational Coaching (a Dutch research consultancy) to explore the pros and cons of implementing vanpooling programs in the Netherlands. After discovering that the possibilities for successful vanpooling existed, Organizational Coaching was then asked to establish pilot projects.

The pilot process was carried forth and the outcome revealed obstacles hindering the widespread adoption of vanpooling in general, including high van prices and lack of HOV lanes. Nonetheless, vanpooling pilot programs confirmed user satisfaction and support, and changes are currently taking place in the Netherlands that are making the future implementation of vanpooling programs likely. Political pressure is growing to change the Dutch fiscal and transportation law in favor of vanpooling, and the Ministry of Transport has advised all relevant government agencies to accept vans in bus lanes [35]. More common than vanpooling in Europe are "employee" or company buses that transport employees from pick-up points near their homes to work at large facilities. 


\section{Future Directions of TDM in Europe}

MOST (Mobility Management Strategies For the Next Decade) [46] is an attempt at implementing pilot projects in 32 European cities spanning over both traditional (companies, schools) and new niche areas such as tourism and new planning sites. The scope of the project is to improve access to transportation for all sectors and to foster positive attitudes toward sustainable mobility. The development of an evaluation framework in the form of a clear guide and impact assessment of the strategies is called MOST MET (MOST Monitoring and Evaluation Toolkit) Project assessment is evaluated by the reduction in vehicle kilometers and the toolkit outlines the entire process for data collection and analysis in this process.

In the education sector, a traditional area in pilot projects, MOST [46] promoted traffic safety both to parents and school officials along with presenting sustainable alternatives to methods being used to transport children. For instance, in Limburg, Belgium, officials implemented four separate projects in a "step-by-step" approach, first promoting a "carfree" school week encouraging other modes like cycling causing an increase $23 \%$ in this mode. Subsequent steps led to the development of a comprehensive plan for the province that aimed to integrate infrastructure development while essentially ensuring mobility management. In the tourism sector, MOST sought to encourage visitors to utilize public transit to relieve some strain on the transport system during peak tourist times.

In Malaga, Spain, a detailed long-term development plan for mobility management and transportation infrastructure was developed in which a dedicated "tourist bus service" was implemented, information leaflets distributed and a smart-card service initiated all to improve the level of service provided.

MOST strategies have also been applied in site development, incorporating new strategies for alternative sustainable mobility and congestion reduction. In Bremen, Germany, the planning of Botanika (a local rhododendron park) included planning for a "pedestrian guidance system" and information dissemination at the park café concerning public transport to park visitors.

The MOST MET presents some suggestions for Mobility Management projects that are to be evaluated:

๑ Embrace evaluation

- Set measurable objectives

口 Build monitoring and evaluation intro planning

- Monitor and evaluate continuously

- Maintain objectivity

口 Monitor users and their activities

口 Evaluate and report results

Given these methods are utilized in evaluating a MOST project there is a clear opportunity to make an accurate assessment of the impact of the project. 


\section{Conclusion}

Certain European counties are utilizing mobility management strategies to impressive and significant effect. Countries such as Germany have made efforts to enhance public awareness about sustainable travel, and recently more emphasis has been placed on educating children before their commuting habits are formed.

The United Kingdom is investigating the feasibility of green commuter plans, such as exploring new taxation plans that favor public instead of private travelers. In addition, road pricing has been implemented in London, and the city has undertaken a large-scale media campaign entitled "Do your bit" [53].

Widely considered vanguard in its implementation of mobility management strategies, the Netherlands has taken large strides in the improvement of pedestrian conditions, promoting public transportation and bike use, implementing carpooling and park and ride systems, and discouraging private travel. It would be a mistake, however, to assume that all countries in Europe are as advanced in their creation of transport demand strategies as the United Kingdom and the Netherlands.

In fact, there are some countries in which the idea of mobility management is just starting to take root, and some in which few noteworthy sustainable mobility strategies exist. Nonetheless, countries such as England and the Netherlands represent a significant trend within the European Union, recognizing the need to curb private car use and promote sustainable modes of travel.

A final and accurate summation on the feasibility of mobility management strategies is difficult to attain, since many measures and projects are in varying stages of development and implementation. One important lesson gleaned from years of research---and an attitude more commonly adopted among TDM professionals---is the view of mobility management as a continual process. Instead of viewing TDM as a final goal to be realized, mobility management instead should be treated as a never-ending evolution and adaptation, never reaching completion but always striving to improve mobility with feasible and sustainable methods.

Some strategies have already proven successful and will likely play an integral role in the evolution of mobility management in the future:

- Promotion of information-based forms of mobility

- Alternation of infrastructure to favor pedestrians and bicyclists

- Public transport improvements

- Road pricing

- Green commuter plans

- Carsharing and vanpooling

- Mobility information centers

The transferability of these strategies to all locales is open to question. For instance, cities like Freiburg and Berlin, Germany, and Vienna, Austria have developed and continue to 
develop extensive and impressive bicycle networks, and in the Netherlands, pedestrian conditions are so favorable that there are 17 million bicycles nationally, more bicycles than people. It would be unreasonable to expect all cities to promote such widespread bicycle use, since some infrastructure, climates and terrain are unaccommodating to certain forms of low-tech mobility. Similarly, the public transport systems of other locales may not facilitate those particular cities being participants of the car-free network, of which Barcelona, Spain; Nottingham, England; and Turin, Italy are a part. On the other hand, mobility information centers, green commuter plans, alternative work schedules, and telework have been deployed in various cities with relative ease and success.

Whatever the mobility management strategy being implemented, a number of reports seem to agree that a combination of factors needs to be present to ensure maximum success. One of the foremost recent trends is educating the public about personal responsibility, and in the process reducing the stigma attached to public transport use. Eventually, the goal should be to make public transport more comfortable, efficient, and cost-effective than private vehicle use. The process of luring travelers to public transportation from private vehicle use should involve both incentives and disincentives.

Furthermore, tax schemes, legislation and the creation or alteration of infrastructure should prioritize pedestrians and sustainable mode users over those who travel by car. A smooth integration of modes and convenient access for commuters is key to ensuring optimum ridership. Aside from these factors, mobility management should be approached as a continuous process, since in a world in which transport demand is exponentially growing, measures to limit the impact of traffic on the economy, environment and infrastructure will always need to be made.

What can the TDM professional in the U.S learn from this growing European Experience? Clearly there are some key differences in the environment in which TDM is implemented. In Europe, the carpool mode is brand new as a recognized alternative to promote. Public transport and bicycle mode shares are significantly higher in most places in Europe as compared to the U.S., with its taxation policy that tends to favor cars more than taxation policies in Europe.

Even with all these differences, the U.S. can certainly learn a lot from European TDM experience. First, the Europeans have adopted and improved upon U.S. TDM measures, such as carpool matching, vanpooling, and the creation of TDM plans at employment sites. Second, TDM is integrated into national transport policy in Europe, whereas in the U.S. it is one local option for congestion relief and air quality. Finally, the Europeans have improved on the marketing of TDM by often promoting sustainable transport as a lifestyle choice rather than as an alternative. European TDM experience also stresses a more personalized, consultative approach through mechanisms like Mobility Centers. Additional information about successful TDM strategies is available in the annotated bibliography accompanying this report. 